\title{
Therapeutic inhibition of Mcl-1 blocks cell survival in estrogen receptor-positive breast cancers
}

\author{
Michelle M. Williams', David L. Elion', Bushra Rahman², Donna J. Hicks², Violeta \\ Sanchez ${ }^{3}$ and Rebecca S. Cook ${ }^{1,2,4,5}$ \\ ${ }^{1}$ Program in Cancer Biology, Vanderbilt University, Nashville, TN 37232, USA \\ ${ }^{2}$ Department of Cell and Developmental Biology, Vanderbilt University, Nashville, TN 37232, USA \\ ${ }^{3}$ Department of Medicine, Vanderbilt University Medical Center, Nashville, TN 37232, USA \\ ${ }^{4}$ Department of Biomedical Engineering, Vanderbilt University, Nashville TN 37232, USA \\ ${ }^{5}$ The Vanderbilt-Ingram Cancer Center, Vanderbilt University Medical Center, Nashville, TN 37232, USA \\ Correspondence to: Rebecca S. Cook, email: Rebecca.cook@vanderbilt.edu \\ Keywords: $\mathrm{MCl}-1$; ABT-263 resistance; mTORC 1 signaling; luminal breast cancers \\ Received: April 23, $2019 \quad$ Accepted: June 14, $2019 \quad$ Published: September 10, 2019 \\ Copyright: Williams et al. This is an open-access article distributed under the terms of the Creative Commons Attribution License \\ 3.0 (CC BY 3.0), which permits unrestricted use, distribution, and reproduction in any medium, provided the original author and \\ source are credited.
}

\section{ABSTRACT}

Cancers often overexpress anti-apoptotic Bcl-2 proteins for cell death evasion, a recognized hallmark of cancer progression. While estrogen receptor (ER)-a+ breast cancers express high levels of three anti-apoptotic $\mathrm{Bcl}-2$ family members (Bcl-2, Bcl-xL, and Mcl-1), pharmacological inhibition of $\mathrm{Bcl}-2$ and/or $\mathrm{Bcl}-\mathrm{xL}$ fails to induce cell death in ERa+ breast cancer cell lines, due to rapid and robust $\mathrm{Mcl}-1$ upregulation. The mechanisms of acute $\mathrm{Mcl}-1$ upregulation in response to $\mathrm{Bcl}-2$ / $\mathrm{Bcl}-\mathrm{xL}$ inhibition remain undefined in in ERa+ breast cancers. We report here that blockade of $\mathrm{Bcl}-2$ or $\mathrm{Bcl}-\mathrm{xL}$, alone or together, rapidly induced mTOR signaling in ERa+ breast cancer cells, rapidly increasing cap-dependent $\mathrm{Mcl-1}$ translation. Cells treated with a pharmacological inhibitor of cap-dependent translation, or with the mTORC1 inhibitor RAD001/everolimus, displayed reduced protein levels of $\mathrm{Mcl}-1$ under basal conditions, and failed to upregulate $\mathrm{Mcl}-1$ protein expression following treatment with ABT-263, a pharmacological inhibitor of $\mathrm{Bcl}-2$ and $\mathrm{Bcl}-\mathrm{xL}$. Although treatment with ABT-263 alone did not sustain apoptosis in tumor cells in culture or in vivo, ABT-263 plus RAD001 increased apoptosis to a greater extent than either agent used alone. Similarly, combined use of the selective Mcl-1 inhibitor VU661013 with ABT-263 resulted in tumor cell apoptosis and diminished tumor growth in vivo. These findings suggest that rapid Mcl-1 translation drives ABT-263 resistance, but can be combated directly using emerging $\mathrm{Mcl}-1$ inhibitors, or indirectly through existing and approved mTOR inhibitors.

\section{INTRODUCTION}

The breast epithelium undergoes many dynamic changes throughout a woman's lifetime. The intrinsic apoptotic pathway, which governs caspase-dependent cell death, is essential to maintain proper development and homeostasis during puberty, pregnancy, lactation, and post-lactational involution [1]. Not surprisingly, breast tumors frequently dysregulate this pathway to favor tumor cell survival, often through upregulation of anti-apoptotic Bcl-2 family proteins (Bcl2-A1, Bcl-2, Bcl-xL, Bcl-w, and Mcl-1) [2]. Anti-apoptotic Bcl-2 proteins bind to proapoptotic factors to prevent functional activation of the apoptotic pathway [3]. Specifically, anti-apoptotic Bcl-2 proteins either 1) bind to Bcl-2 effectors (Bak and Bax) to block pore formation in the outer mitochondrial membrane 
caused by Bak/Bax oligomerization [4], or 2) sequester Bcl-2 activators (e.g., Bim, Bid, and Puma), which facilitate Bak/Bax oligomerization [5]. The dynamic and tightly regulated interactions between anti-apoptotic and pro-apoptotic Bcl-2 family proteins will tip the balance of cellular decisions towards or away from apoptosis.

Over 250,000 patients in the United States were diagnosed with invasive breast cancer in 2018, resulting in over 40,000 deaths. Estrogen Receptor (ER)- $\alpha$ positive breast cancer represents $60-70 \%$ of all breast cancers diagnosed. Notably, up to $70 \%$ of ER+ breast cancers express Bcl-2 [6], although Bcl-2 is expressed at low levels in other breast cancer subtypes $[7,8]$. In contrast, Bcl-xL and Mcl-1 are widely expressed in ER+ breast cancers, as well as in HER2-amplified and triple negative breast cancers (TNBC) [7], both in pre-malignant lesions [9] and in high grade tumors [8]. Interestingly, $\mathrm{Mcl}-1$ protein expression reportedly is higher in ER $\alpha$-positive specimens $[7,10]$. At the genetic level, MCL1 is the most frequently amplified anti-apoptotic Bcl-2 family member in ER+ breast cancers [11]. Further, Mcl-1 protein expression correlates with poor patient survival in breast cancers regardless of subtype [12]. These observations support the intense research efforts into therapeutic targeting of antiapoptotic Mcl-1 in breast cancers.

Because anti-apoptotic Bcl-2 family proteins neutralize pro-apoptotic effectors (Bak and Bax) and activators (Bim, Bid, and Puma) specifically through their Bcl-2 homology-3 (BH3)-domain binding pocket, a class of small molecular inhibitors that bind specifically within the $\mathrm{BH} 3$-domain binding pocket potently block interactions between anti-apoptotic proteins and their pro-apoptotic targets [13]. These 'BH3-mimetics' liberate $\mathrm{BH} 3$ motif-containing proteins (Bim, Bax, Bak, etc.) from interactions with anti-apoptotic Bcl-2 proteins, allowing pro-apoptotic effectors and activators to engage the intrinsic apoptotic pathway. BH3-mimetics targeting Bcl2 and/or Bcl-xL have been successful as single agents in clinical studies of hematological malignancies [14-16]. However, single agent inhibition of Bcl-2 (using ABT199) or dual inhibition of Bcl-2/Bcl-xL (using ABT737 or ABT-263) was ineffective in pre-clinical models of human TNBC [10]. Similarly, studies in pre-clinical models of $\mathrm{ER} \alpha+$ breast cancers showed that ABT-263 was ineffective as a single agent, in large part due to rapid Mcl1 upregulation [17], although the molecular mechanism(s) driving compensatory Mcl-1 upregulation in response to $\mathrm{Bcl}-2 / \mathrm{Bcl}-\mathrm{xL}$ inhibition in ER+ breast cancers are not yet clearly defined.

Herein we show that increased Mcl-1 translation upon ABT-263 treatment drives survival of ERa+ breast cancer cells. ABT-263 treatment combined with a translation inhibitor, or combined with the mTOR inhibitor RAD001/everolimus, blocked Mcl-1 protein upregulation. Importantly, we found that the novel Mcl-1 small molecular weight inhibitor VU661013 blocked Mcl-
1 activity in ER+ breast cancer cells, increased caspasemediated apoptosis in ER+ tumor cells, and when used in combination with ABT-263, produced robust killing of $\mathrm{ER} \alpha+$ tumor cells in culture and in vivo.

\section{RESULTS}

\section{Cap-dependent translation is required for Mcl-1 upregulation in response to $\mathrm{Bcl}-2 / \mathrm{Bcl}-\mathrm{xL}$ inhibition}

Although combined inhibition of Bcl-2 and Bcl$\mathrm{xL}$ using ABT-263 is capable of inducing apoptosis in $\mathrm{ERa}+$ breast cancer cells [17], rapid Mcl-1 upregulation in response to ABT-263 limits the extent to which apoptosis is induced in these cells. To understand the mechanisms contributing to Mcl-1 upregulation upon combined Bcl-2/Bcl-xL inhibition, we treated ERa+ cells, including HCC1428, MCF7, and T47D, with ABT$263(1 \mu \mathrm{M})$ or with vehicle control for 16 hours (hr), a time point at which Mcl-1 is upregulated in response to ABT-263. Relative MCL1 transcript levels measured by quantitative real-time polymerase chain reaction (qRTPCR) remained unchanged in HCC1428 and MCF7 cells treated with ABT-263, and were down-regulated in T47D cells treated with ABT-263 (Figure 1A), suggesting that transcript levels do not contribute significantly to changes in Mcl-1 protein levels upon ABT-263 treatment. Protein stability was assessed in cells treated with ABT-263 using cycloheximide (CHX) to block new protein synthesis. Mcl-1 protein levels assessed by western analysis revealed that Mcl-1 levels were upregulated in cells treated with ABT-263, as expected (Figure 1B). However, Mcl-1 diminution following $\mathrm{CHX}$ chase occurred at similar rates in cells treated with ABT-263 and in control treated cells (Figure 1B-1C). These findings suggest that $\mathrm{Mcl}-1$ protein stabilization is not a major driver of Mcl-1 upregulation in response to ABT-263 in ER $\alpha+$ breast cancer cells.

Increased cap-dependent translation of MCL1, particularly under conditions of cellular stress, reportedly contributes to $\mathrm{Mcl}-1$ protein upregulation $[18,19]$. This possibility was tested in ER $\alpha+$ cells treated with ABT263 using a pharmacological inhibitor of cap-dependent translation, 4E1RCat [20]. While Mcl-1 protein levels were increased in cells treated $16 \mathrm{hr}$ with ABT-263, inhibition of cap-dependent translation with 4E1RCat blocked Mcl-1 upregulation following ABT-263 treatment in each cell line (Figure 1D).

Because ABT-263 blocks activity of Bcl-2 and Bcl$\mathrm{xL}$, both of which are expressed in ER+ breast cancer cells, we tested the impact of selective Bcl-2 inhibition versus selective $\mathrm{Bcl}-\mathrm{xL}$ inhibition on $\mathrm{Mcl}-1$ protein levels using the Bcl-2 selective inhibitor ABT-199 [16], and the Bcl-xL selective inhibitor A1155463 [21]. As expected, MCL1 transcripts were not increased upon treatment with ABT-199 $(1 \mu \mathrm{M})$ or A1155463 $(1 \mu \mathrm{M})$ 
(Supplementary Figure 1A-1B), similar to what was seen in cells treated with the dual Bcl-2/Bcl-xL inhibitor ABT-263. Interestingly, western analysis did not reveal a pattern specifically implicating either Bcl-2 or Bcl-xL inhibition as a main driver of Mcl-1 upregulation across all three ER+ breast cancer cell lines tested (Figure 1E). Modest Mcl-1 upregulation was seen in HCC1428 and T47D cells treated upon Bcl-2 inhibition with ABT199, but not in MCF7 cells treated with ABT-199 alone.
MCF7 and T47D cells, but not HCC1428, increased Mcl1 in response to inhibition of Bcl-xL using single agent A1155463. Importantly, combined inhibition of Bcl-2 and Bcl-xL using ABT-199 plus A1155463, or using the dual inhibitor ABT-263, induced Mcl-1 expression in HCC1428, MCF7 and T47D cells more robustly than inhibition of Bcl-2 inhibition alone or Bcl-xL inhibition alone. Mcl-1 upregulation seen in cells treated with the combination of ABT-199 and A1155463 was abrogated
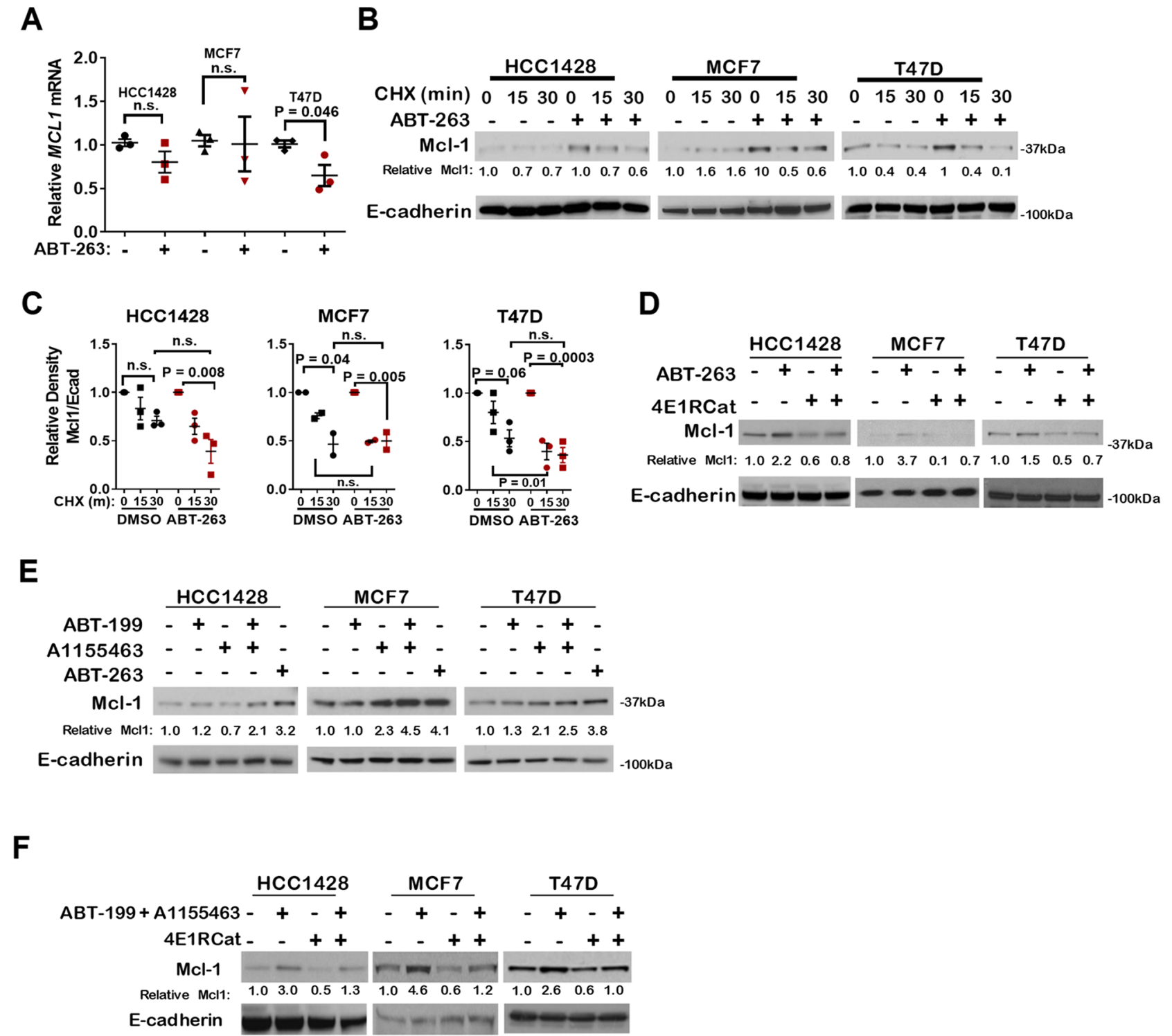

Figure 1: Pharmacological inhibition of Bcl-2 and/or Bcl-xL increases Mcl-1 expression through cap-dependent translation. (A) Relative MCL1 transcript levels were determined by RT-qPCR after treatment with $1.0 \mu \mathrm{M}$ ABT-263 for 16 hrs. Values were standardized to DMSO control for each cell line. Each data point represents the average of three technical replicates, midlines are the average of the biological replicates. P-value calculated using Student's unpaired two-tailed t-test. (B-C) Western analysis of lysates from cells treated with $1.0 \mu \mathrm{M}$ ABT-263 for $16 \mathrm{hrs}$ then chased with cyclohexamide (CHX) for 0-30 minutes. (B) Representative images are shown. Antibodies used are shown to the left of each panel. (C) Average Mcl-1 band density ( \pm S.E.) is shown, N = 3. Two-way ANOVA and Bonferroni post hoc test. (D-F) Western analysis of whole cell lysates were harvested from cell treated with $1.0 \mu \mathrm{M}$ ABT-263, ABT199, A-1155463, or ABT-199 + A-1155463 for 16 hrs. Where indicated, $5.0 \mu \mathrm{M}$ 4E1RCat was added for the final 4 hrs. Antibodies used are shown to the left of each panel. 
upon blockade of cap-dependent translation (Figure 1F), similar to what was found in cells treated with ABT263. These findings are consistent with previous reports describing increased translation of $\mathrm{Mcl}-1$ in Bcl-xLimpaired breast cancer cells harboring PIK3CA activating mutations (17), a mutation that increases signaling through phosphatidyl inositol-3 kinase (PI3K) and its downstream effector mTOR. However, we extend these findings to include cells that are PIK3CA wild-type (HCC1148), and in response to Bcl-2 inhibition. These results suggest that $\mathrm{ER} \alpha+$ breast cancer cells may rely heavily on capdependent translation of $M C L 1$ to drive rapid and potent Mcl-1 protein upregulation.

\section{Signaling through mTORC1 controls Mcl-1 protein upregulation upon loss of $\mathrm{Bcl}-2 / \mathrm{Bcl}-\mathrm{xL}$ activity}

Previous studies demonstrate that mTOR complex 1 (mTORC1) is a key regulator of protein translation, including cap-dependent translation, and as such is a dominant driver of tumorigenesis [as reviewed in [22]]. We tested the hypothesis that mTORC1 signaling may drive Mcl-1 upregulation upon Bcl-2/Bcl-xL blockade. We found that, in serum-starved cells treated with ABT263 for $16 \mathrm{hr}$, phosphorylation of the mTORC1 substrate 4-Elongation Initiating Factor-Binding Protein-1 (4EBP1) was increased (Figure 2A), consistent with the notion that mTORC1 signaling may increase in response to Bcl-2/ Bcl-xL inhibition. Notably, 4EBP1 is a key translational inhibitor whose activity is neutralized by mTORC1mediated phosphorylation, thus enabling translation initiation to occur [23]. RAD001 (everolimus) [24], a rapalogue that inhibits the activity of $\mathrm{mTORC} 1$, was used to block mTORC1 signaling in ER+ breast cancer cells. In cells treated for $16 \mathrm{hr}$ with RAD001 (200 nM), Mcl1 protein levels were diminished as compared to what was seen in control-treated cells (Figure 2B). In addition to depleting Mcl-1 levels, RAD001 treatment for $4 \mathrm{hr}$ increased caspase-3/7 activity in HCC1428, MCF7, and T47D cells (Figure 2C). Increased caspase 3/7 activity was maintained through at least $48 \mathrm{hr}$ in MCF7 cells, but not in HCC1428 or T47D cells. Interestingly, adenoviralmediated overexpression of Mcl-1 (Figure 2D) abrogated RAD001-induced caspase-3/7 activation over $4 \mathrm{hr}$ of treatment (Figure 2E), and partially blocked RAD001mediated growth inhibition over 7 days of growth (Figure $2 \mathrm{~F}$ ), suggesting that decreased expression of $\mathrm{Mcl}-1$ is a major contributor to the growth inhibitory effects of mTOR inhibitors.

\section{mTORC1 inhibition depletes Mcl-1 expression and activity induced by ABT-263}

To explore the role of mTORC1 signaling in upregulation of Mcl-1 specifically upon treatment of cells with ABT-263, we treated cells with ABT-263 in the presence or absence of RAD001 for $16 \mathrm{hr}$. While ABT-263 induced Mcl-1 protein upregulation in ER $\alpha+$ breast cancer cells, RAD001 abrogated Mcl-1 induction by ABT-263 (Figure 3A). A proximity ligation assay (PLA) detecting molecular proximity between Mcl1 and Bim has been used previously as a measure of Mcl-1 activity [11, 25]. PLA confirmed increased Mcl-1 activity in ER $\alpha+$ breast cancer cells treated with ABT-263, while showing that Mcl-1 activity was diminished in cells treated with RAD001, even in those cells treated with ABT-263 (Figure 3B-3C). Consistent with this observations, treatment of ER+ breast cancer cells with the combination of RAD001 plus ABT-263 increased caspase-3/7 activity (Figure 3D) and decreased cell growth (Figure 3E) to a greater extent than either inhibitor alone.

To confirm these findings in vivo, we treated mice harboring MCF7 xenografts with ABT-263 (20 $\mathrm{mg} / \mathrm{kg}$, daily) in combination with RAD001 (1 mg/ $\mathrm{kg}$, daily) for 16 days. Immunohistochemistry (IHC) demonstrated that phosphorylation of the mTORC1 substrate ribosomal protein p70 S6-kinase (S6K) was decreased after RAD001 treatment (Supplementary Figure 2), confirming inhibition of mTORC1 signaling. IHC detection of Mcl-1 protein expression in MCF7 tumors showed that while ABT-263-treated tumors upregulated Mcl-1 protein levels, RAD001-treated tumors displayed reduced Mcl-1 protein expression as compared to vehicle-treated or ABT-263 treated tumors (Figure 3F). Importantly, ABT-263-mediated upregulation of Mcl-1 was blocked by RAD001, which restrained Mcl-1 to baseline levels, further supporting the idea that ABT-263 treatment relies on mTORC1mediated Mcl-1 upregulation, which can be blunted by mTORC1 inhibitors.

Terminal dUTP Nick-End Labeling (TUNEL) analysis of MCF7 xenografts collected at treatment day 16 showed that the combination of ABT-263 + RAD001 induced the greatest rate of tumor cell death (Figure 3G and Supplementary Figure 3), while tumor cell proliferation, measured by phosphohistone $\mathrm{H} 3$ staining, was unaffected by treatment with RAD001 or ABT-263 as compared to RAD001 alone (Supplementary Figure 4). Although ABT-263 alone (N $=10$ ) did not significantly alter the growth of MCF7 tumors as compared to those treated with vehicle control (Figure 3H), RAD001 $(\mathrm{N}=7)$ decreased MCF7 tumor growth by nearly $35 \%$ as compared to controls $(\mathrm{N}=9)$. However, tumor growth was blocked using the combination of RAD001 and ABT-263 throughout the 16-day treatment period $(\mathrm{N}=7)$, confirming that mTORC1 inhibition restrained Mcl-1 upregulation following $\mathrm{Bcl}-2 / \mathrm{Bcl}-\mathrm{xL}$ inhibition, increasing the therapeutic effect of ABT-263 in ERa+ breast cancer xenografts in vivo. 
The Mcl-1 selective inhibitor VU661013 blocks Mcl-1 activity and induces apoptosis in ER+ breast cancer cells

The Mcl-1 selective inhibitor VU661013 previously was shown to induce tumor cell killing in pre-clinical models of TNBC and acute myelogenous leukemia $[26,27]$, but has not yet been tested in models of ER+ breast cancer. PLA confirmed that after $4 \mathrm{~h}$ treatment with VU661013 $(1 \mu \mathrm{M})$, Mcl-1 interactions with Bim was substantially reduced to less than $50 \%$ of what was seen in control-treated cells (Figure 4A-4B). These
A

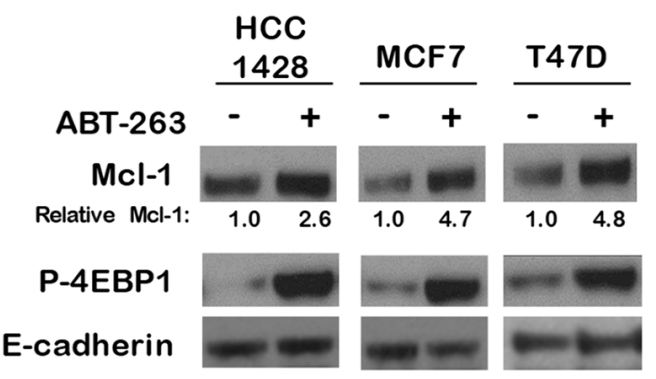

C
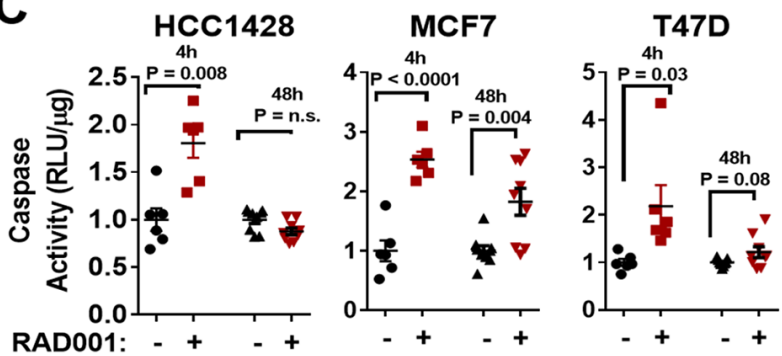

E

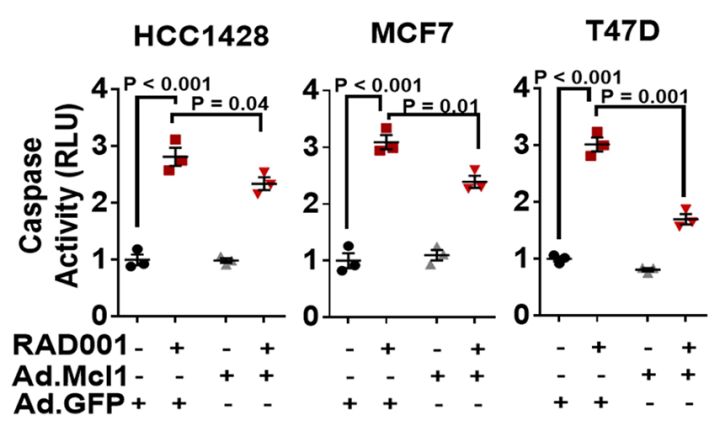

B

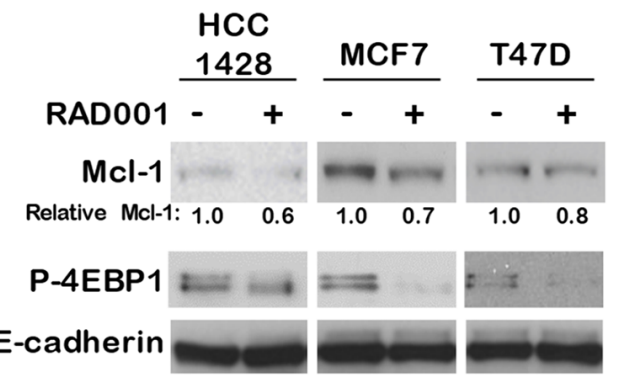

D

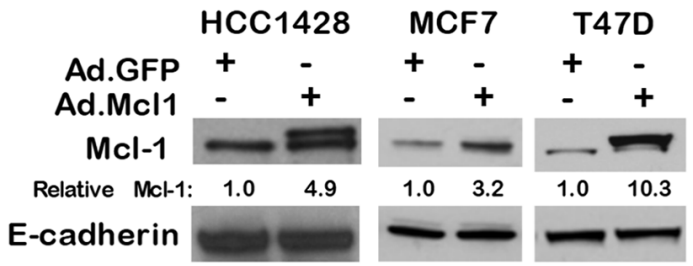

$\mathbf{F}$
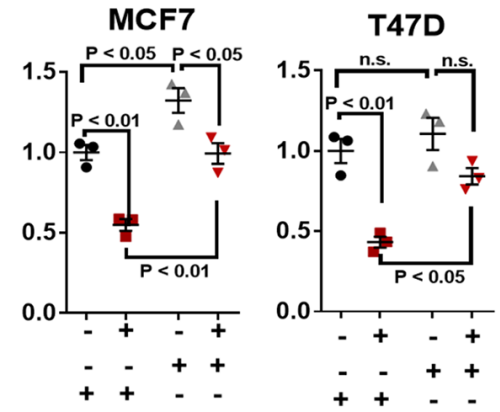

Figure 2: mTORC1 inhibition induces cell death through Mcl-1 depletion. (A) Cells were treated with DMSO or with ABT$263(1 \mu \mathrm{M})$ for $16 \mathrm{hrs}$, and whole cell lysates were assessed by western analysis using antibodies shown at left of each panel. Relative Mcl-1 calculated using densitometry analysis of Mcl-1 bands from western analysis films (corrected for E-cadherin densitometry analysis) using ImageJ software. (B) Cells were treated with DMSO or with RAD001 (200 nM) for 16 hrs (B) and whole cell lysates were assessed by western analysis using antibodies shown at left of each panel. Relative Mcl-1 calculated as described in panel A. (C) Caspase-3/7 activity

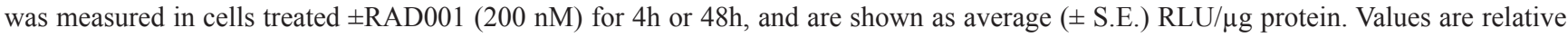
to the average value measured in DMSO-treated cells for each cell line. $\mathrm{N}=6-9$, Student's unpaired two-tailed t-test. (D) Western analysis of whole cell lysates harvested 48 hrs after transduction with adenoviral Mcl-1 (Ad.Mcl1) or Adenoviral GFP (Ad.GFP). Relative Mcl-1 levels were determined as described in panel A. (E) Caspase-3/7 activity was measured $72 \mathrm{hrs}$ after adenoviral transduction. RAD001 (200 $\mathrm{nM}$ ) or DMSO was added for the final $4 \mathrm{hrs}, \mathrm{N}=3$, each assessed in triplicate. Two-way ANOVA with Tukey's multiple comparisons test. (F) Single cell suspensions were seeded in 3D-matrix at $24 \mathrm{hr}$ post-transduction, and cultured with DMSO or $200 \mathrm{nM}$ RAD001 for 7 days. Average number of colonies/200x-field is shown for 3 experiments, each assessed in duplicate. All values for each cell line were set relative to the average number of colonies measured in Ad.GFP-transduced cells treated with DMSO. Two-way ANOVA with Tukey's multiple comparisons test. 
A

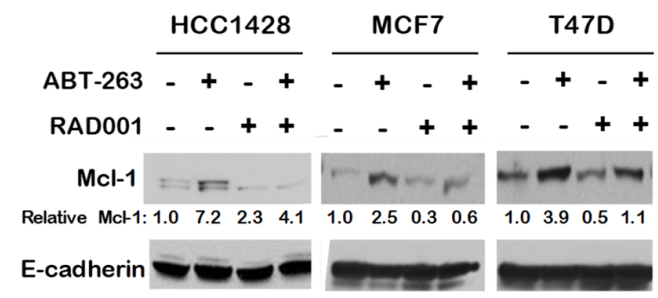

C

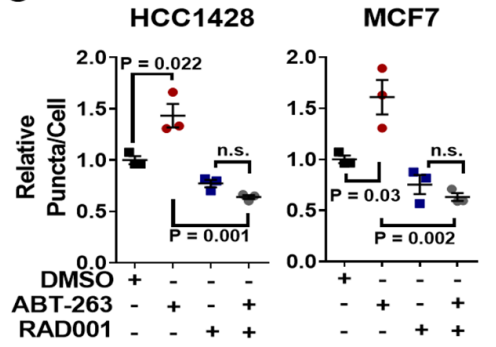

E
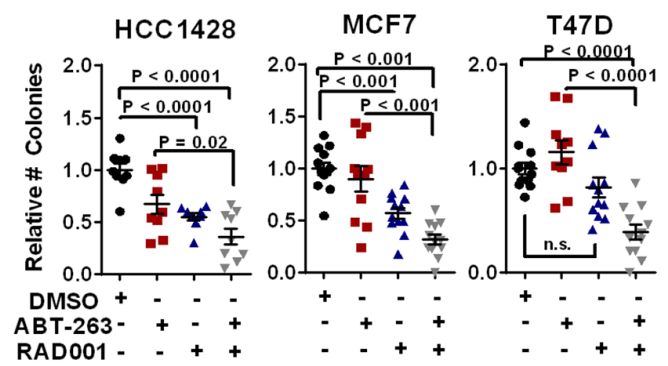

G

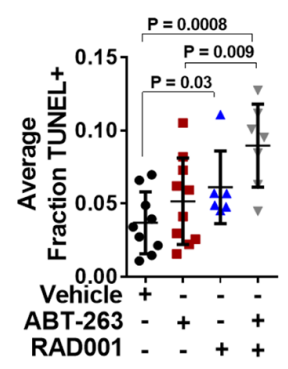

B

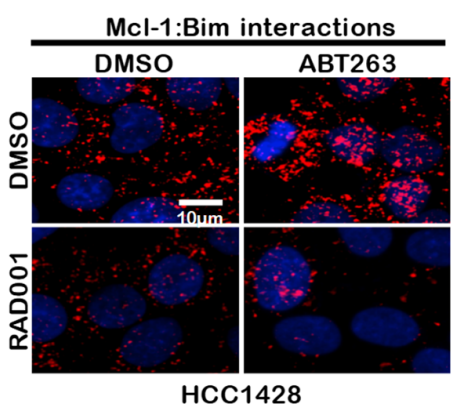

D

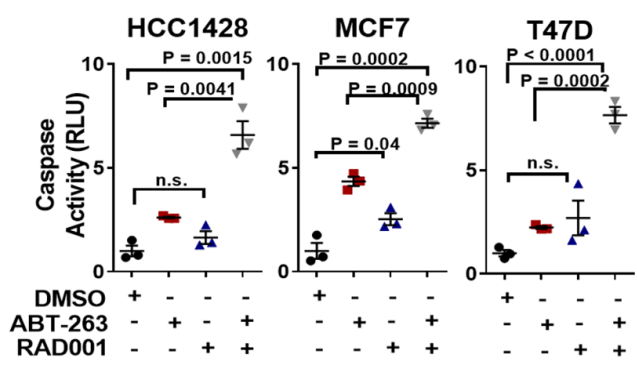

$\mathbf{F}$
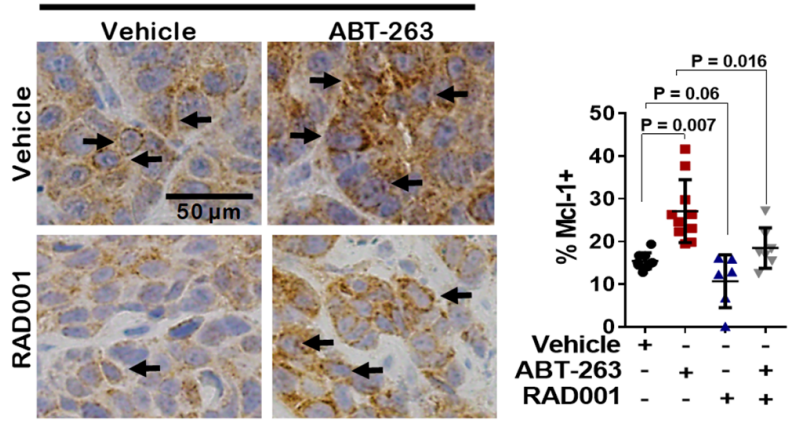

H

MCF7 xenografts

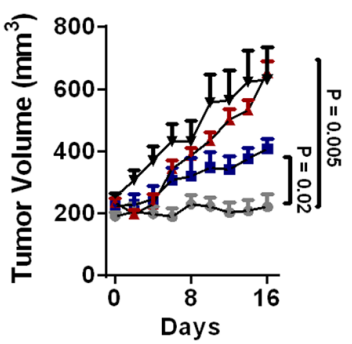

- ABT-263 + RAD001

- RAD001 (1.0mg/kg)

‡ ABT-263 $(20 \mathrm{mg} / \mathrm{kg})$

$\rightarrow$ Vehicle

Figure 3: Inhibition of mTORC1 blocks Mcl-1 upregulation in response to ABT-263, and sensitizes ERa+ breast cancers to ABT-263-mediated cell death. (A) Western analysis of whole cell lysates harvested from cells treated with $1.0 \mu \mathrm{M}$ ABT$263 \pm 200 \mathrm{nM}$ RAD001 for $16 \mathrm{hr}$. Antibodies used are shown at left. Densitometry (Image J software) was used to determine relative Mcl-1 protein levels. (B-C) PLA using antibodies against Bim and Mcl-1 was conducted on methanol fixed cells after treatment with $1.0 \mu \mathrm{M}$ ABT-263 $\pm 200 \mathrm{nM}$ RAD001 for $16 \mathrm{hrs}$. Representative images are shown (B) red puncta = Mcl-1:Bim proximity; blue $=$ hoescht staining of nuclei. Quantitation is shown (C) Data points represent the average number of puncta/nucleated cell for 20 fields of view per sample, $\mathrm{N}=3$. Two-way ANOVA followed by Tukeys multiple comparisons test. (D) Caspase activity was measured in cells treated with $1.0 \mu \mathrm{M}$ ABT-263 $\pm 200 \mathrm{nM}$ RAD001 for $4 \mathrm{hr}$. Data points are the average RLUs corrected for total protein in three technical replicates, midlines are the average RLUs corrected for total protein of three biological replicates ( \pm S.E.). The average RLUs in control cells for each cell line was set at a value of 1, two-way ANOVA followed by Tukeys multiple comparisons test. (E) Cells were cultured 7d in $1.0 \mu \mathrm{M} \mathrm{ABT}-263 \pm$ $200 \mathrm{nM}$ RAD001. Average relative cell number ( \pm S.E.) is shown, $\mathrm{N}=6-9$, Two-way ANOVA followed Tukey's multiple comparisons test. (F-H) MCF7 tumor xenografts in athymic mice were treated with ABT-263 $(20 \mathrm{mg} / \mathrm{kg})$ and $/$ or RAD001 $(1 \mathrm{mg} / \mathrm{kg})$ for 16 days. (F) IHC was used to visualize Mcl-1 expression on treatment day 16. Representative images are shown at the left, and the percentage of cells staining positive for Mcl-1 is shown at the right. Data points present the average in three fields per sample. Midlines represent the average across 6-9 samples per group. (G) TUNEL analysis was used to detect apoptotic cells, and quantitated as described in panel F. (H) Tumor volume of MCF7 xenografts were measured once every two days beginning on treatment day 0 . Average tumor volume (S.E.) is shown. $\mathrm{N}=6-9$. 
findings were confirmed by assessing co-precipitation of Bim with Mcl-1. While Bim co-precipitation with Mcl1 was seen in control-treated cells, the interaction was blocked in HCC1428 cells treated $4 \mathrm{hr}$ with VU661013 (Figure 4C and Supplementary Figure 5). Consistent with blockade of Mcl-1 activity, treatment of cells for $4 \mathrm{hrs}$ with VU661013 increased Caspase 3/7 activity in ER+ breast cancer cells (Figure 4D). Caspase activity remained modestly, but significantly, elevated through $48 \mathrm{hr}$ of treatment with VU661013. Additionally, growth of cells in monolayer over 7 days was diminished upon treatment with VU661013 (Figure 4E). These results are similar to what was seen in ER+ breast cancer cells expressing short hairpin RNA (shRNA) sequences against MCL1 (shMcl1) (Figure 4F), which displayed increased Caspase 3/7 activity as compared to cells expressing non-targeting control sequences (shControl) (Figure 4G). These results are in agreement with previous reports demonstrating that Mcl-1 knockdown increases caspase-dependent apoptosis in ER+ breast cancer cells, and confirms that the Mcl-1 inhibitor VU661013 reproduces the phenotypic effects of gene-specific Mcl-1 knockdown.

\section{VU661013 combined with ABT-263 increases tumor cell death to a greater extent than either agent alone}

We measured Mcl-1 protein levels in cells treated with VU661013, finding increased Mcl-1 protein expression after $16 \mathrm{hr}$ (Figure 5A). As expected, Mcl-1 expression was also upregulated upon treatment with ABT-263 and remained high in cells treated with the combination of ABT-263 and VU661013. Interestingly, $\mathrm{Bcl}-\mathrm{xL}$ and Bcl-2 levels were not elevated in cells treated with ABT-263 + VU661013. While Caspase 3/7 activity was increased upon treatment with VU661013, we found that caspase $3 / 7$ activity was further increased when cells were treated with the combination of ABT-263+ VU661013 (Figure 5B). These data are consistent with what was seen in ER+ breast cancer cells expressing shRNA sequences against Mcl-1 and treated with ABT263 (Figure 5C), which increased caspase $3 / 7$ activity to a greater extent than Mcl-1 knockdown alone or ABT-263 treatment alone (Figure 5D). Importantly, the combination of ABT-263 with VU661013 potently inhibited growth of tumor cells cultured in monolayer (Figure 5E) similar to the growth inhibition seen with ABT-263 in combination with shRNA sequences knocking down Mcl1 (Supplementary Figure 6).

The growth inhibitory effects of VU661013 were confirmed in vivo using MCF7 xenografts grown in athymic mice. Tumor-bearing mice were treated daily with ABT-263 $(20 \mathrm{mg} / \mathrm{kg})$ alone, or in combination with once weekly treatment with VU661013 (25 mg/kg). Tumor cell death assessed by TUNEL analysis revealed a twofold increase in tumor cell death in samples treated with
VU661013 as a single agent (Figure 5F and Supplementary Figure 7). Although tumors treated with single agent ABT263 did not display statistically increased tumor cell death, tumor cell death was markedly increased in tumors treated with the combination of ABT-263 and VU661013. Tumor volume measurements showed that, while ABT-263 treatment had little impact on tumor volume, VU661013 decreased tumor volume by approximately $25 \%$ versus control-treated tumors (Figure 5G). However, the combination of ABT-263 with VU661013 blocked tumor growth, supporting the hypothesis that Mcl-1 targeting improves treatment response of ER+ breast tumors to ABT-263, and highlighting the potential utility of Mcl-1 inhibitors in ER+ breast cancers.

\section{DISCUSSION}

The anti-apoptotic Bcl-2 family member Mcl-1 is highly expressed in all breast cancer subtypes, although relatively little is known about Mcl-1 in breast tumor biology. With the ongoing development of Mcl-1 specific BH3-mimetics [28, 29], a better understanding of the role of Mcl-1 in breast cancer is imperative. A growing body of data suggests that Mcl-1 may play a strategic role in $\mathrm{ER} \alpha+$ breast cancers, a breast cancer subtype that expresses Bcl-2, Bcl-xL and Mcl-1. Importantly, Mcl-1 is a key survival factor used by several cancers to promote cell survival upon inhibition of Bcl-2 and Bcl$\mathrm{xL}$, including ER+ breast cancers $[17,30]$. We report here that mTOR-dependent MCL1 translation rapidly drives Mcl-1 upregulation in ER+ breast cancer cells treated with ABT-263, or with BH3 mimetics that target Bcl-2 alone (ABT-199) or Bcl-xL alone (A1155463), consistent with the well-established oncogenic role of mTOR in ER+ breast cancers [31, 32]. Also, these findings are supported by reports in other cancers suggesting that cancer cells often use rapid Mcl-1 translation to evade therapeuticallyinduced tumor cell death [33-35]. Previous studies in colon cancers [36], rhabdomyosarcomas [37], lung cancers [38, 39], glioblastomas [40], and ovarian cancers [41] demonstrated that under conditions of cellular duress, including treatment with ABT-263, Mcl-1 protein levels are induced downstream of mTOR signaling. A recent study examining PIK3CA-mutant breast cancers showed that heightened PI3K-mTOR signaling is a key driver of Mcl-1 overexpression in these tumor cells, and that PI3K/mTOR inhibition impaired Mcl-1 expression, increasing PIK3CAmutant cell sensitivity to ABT-263 [17]. Studies presented herein support a wider impact of $\mathrm{mTORC} 1$ signaling on Mcl-1 expression, highlighting the mTORC1-to-Mcl-1 axis in PIK3CA-wild type ER+ breast cancer cells (e.g. HCC1428). Additionally, we found that mTOR inhibition, even in the absence of ABT-263, effectively reduced Mcl1 expression, and induced apoptosis in ER+ breast cancer cells, suggesting that Mcl-1 diminution may contribute to the molecular mechanisms of cell death and growth 
A

PLA measuring Mcl-1:Bim interactions

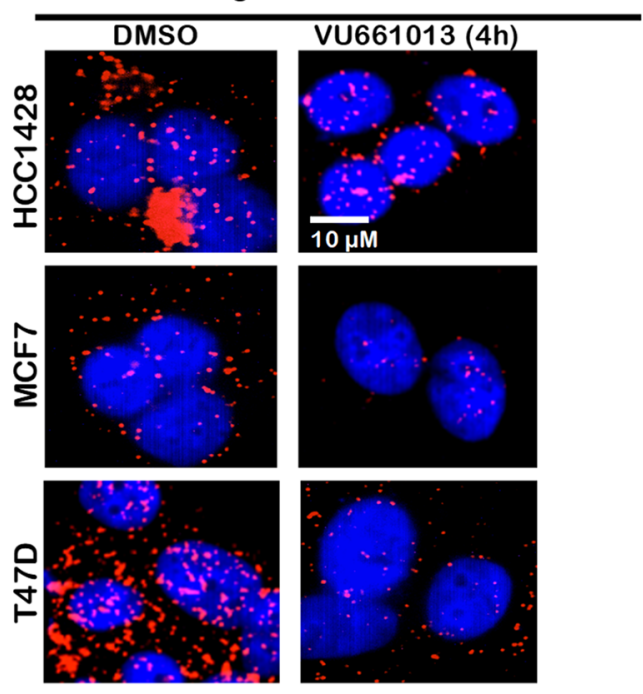

D

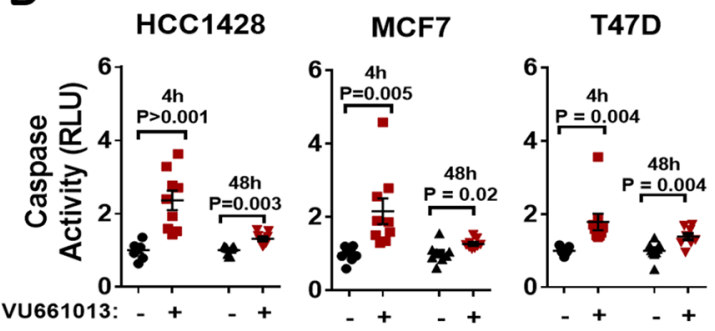

$\mathbf{F}$

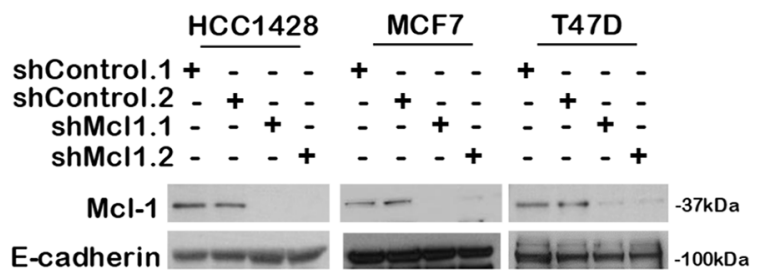

B

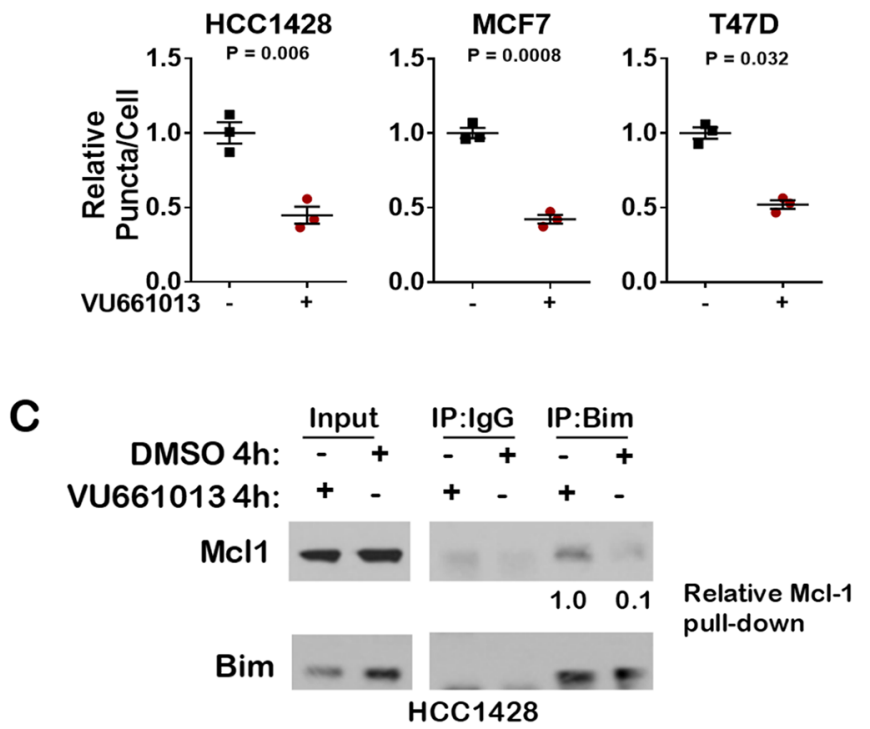

$\mathbf{E}$
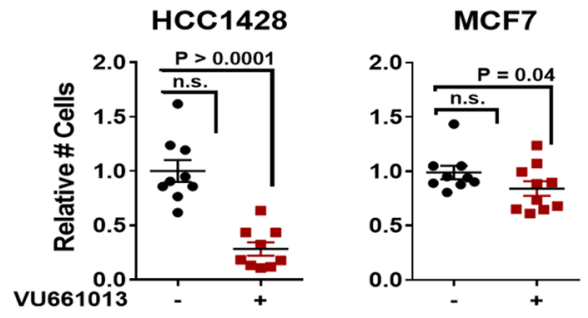

T47D

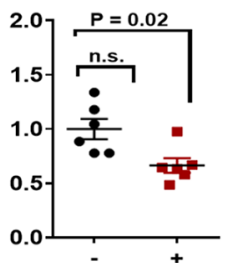

G

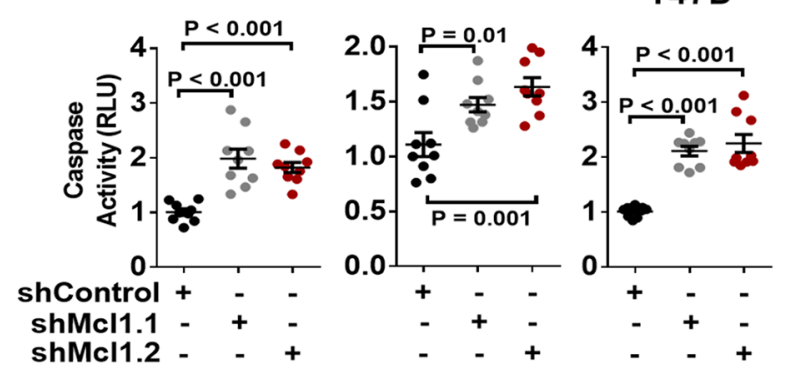

Figure 4: The novel Mcl-1 inhibitor VU-661013 bocks Mcl-1 BIM interaction and induces apoptosis in ER+ breast cancer cells. (A-B) Proximity ligation assay (PLA) using antibodies against Bim and Mcl-1 was conducted on methanol fixed cells after treatment with $1.0 \mu \mathrm{M}$ VU661013 for 4 hrs. (A) Representative images are shown. Mcl-1:Bim proximity, blue = hoescht staining of nuclei. (B) Quantitation is shown. Data points represent the average number of puncta/nucleated cell for 20 fields of view per sample, $\mathrm{N}=3$. Student's T-test. (C) Western analysis of whole cell lysates (input) or Bim immunoprecipates (IP: Bim) from whole cell lysates harvested from cells treated with $1.0 \mu \mathrm{M}$ VU661013 for 4 hrs. Antibodies used for western analysis are shown at left. Densitometry (Image J software) was used to determine relative Mcl-1 protein levels. (D) Caspase 3/7 activity was measured in cells treated with 1.0 $\mu \mathrm{M}$ VU661013 for $4 \mathrm{hr}$ and $48 \mathrm{hr}$. Data points are the average RLUs corrected for total protein in three technical replicates, midlines are the average RLUs corrected for total protein of 6-9 biological replicates ( \pm S.E.). The average RLUs in control cells for each cell line was set at a value of 1, Student's T-test. (E) Cells grown were treated with $1.0 \mu \mathrm{M}$ VU661013 for $7 \mathrm{~d}$. Average relative number of cells per well (plus minus S.E.) is shown, $\mathrm{N}=6-10$, Student's T-test. (F-G) Cells were transduced with lentivirus expressing two distinct MCL1 shRNA sequences, or two distinct non-coding shRNA sequences, and selected with puromycin. (F) Western analysis of pooled clones was used to measure Mcl-1 protein expression. (G) Caspase 3/7 activity was measured in pooled clones of shRNA-expressing cells. Individual data points show the average of two technical replicates, $\mathrm{N}=8-9$ biological replicates. 
inhibition in ER+ breast cancers treated with RAD001. While this idea requires further exploration, this hypothesis is interesting to note in light of the recently published case study in which a patient with late stage MCL1-amplified $\mathrm{ER} \alpha+$ breast cancer treated with aromatase inhibition (anastrozole) and RAD001/everolimus achieved a pathological complete response [42].

While the results shown here suggest that Mcl-1 may be targeted indirectly using mTORC1 inhibitors, there is much excitement over the emerging class of selective Mcl-1 inhibitors. Here, we assessed the Mcl-1 inhibitor VU661013 in ER+ breast cancer cells, finding that VU661013 induced caspase activity, inhibited growth, and induced apoptosis of ER+ breast cancer cells in culture and in vivo. Further, we report that the combined inhibition of Mcl-1 using VU661013 with blockade of $\mathrm{Bcl}-2 / \mathrm{Bcl}-\mathrm{xL}$ using ABT-263 resulted in superior tumor cell killing and tumor growth inhibition in $\mathrm{ER} \alpha+$ breast cancers in culture and in vivo. We confirmed that VU661013 blocked Mcl-1 interactions
A

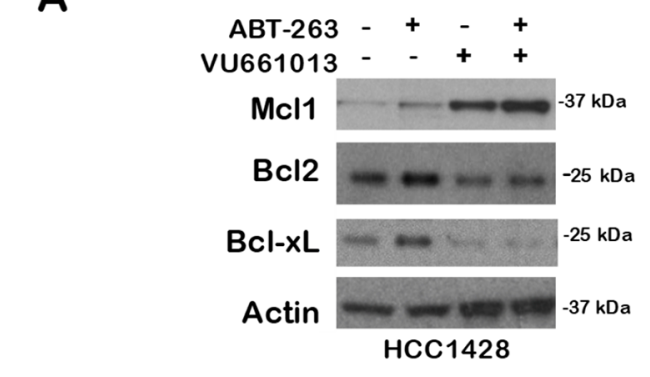

C

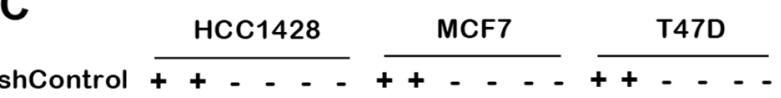

shMcl1.1 - - + + - - - + + - - + + -

shMcl1.2 - - - + + - - - + + - - - + +

ABT-263 - + $+-_{-}++-_{-}++_{-}++_{-}+$

$\mathrm{Mcl}-1$

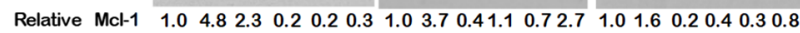

E-cadherin $-\infty-\infty-\infty-\infty-\infty-\infty$
B
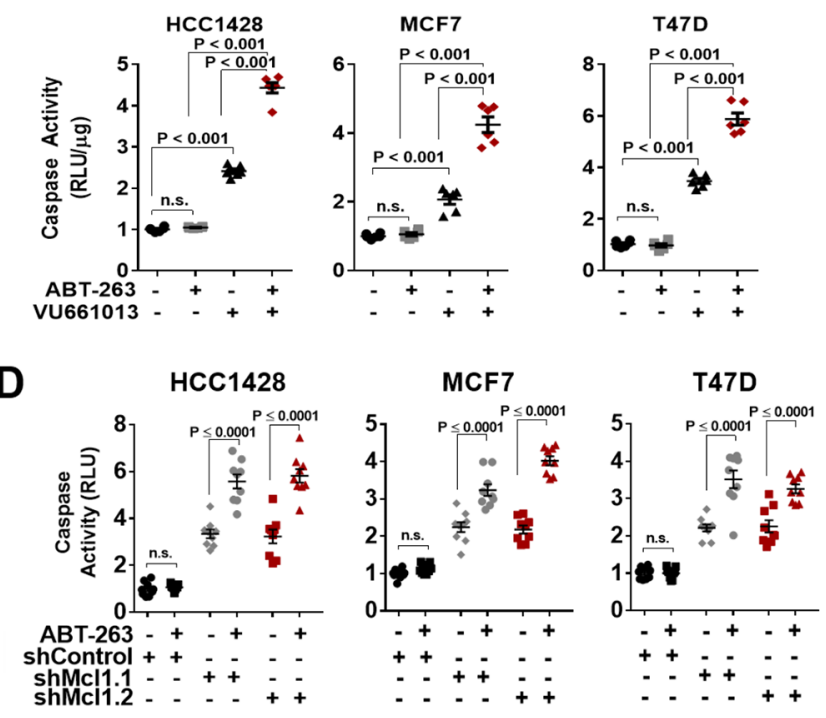

E

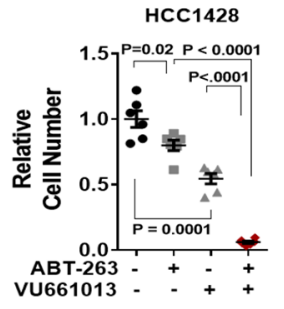

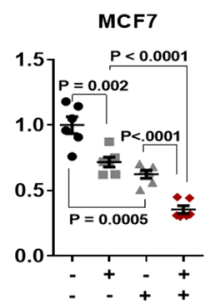

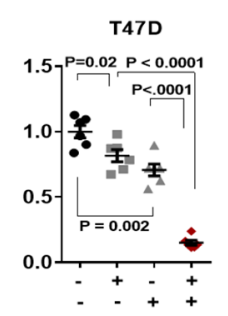

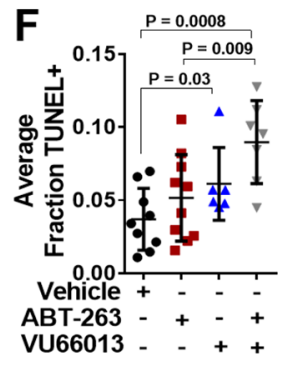

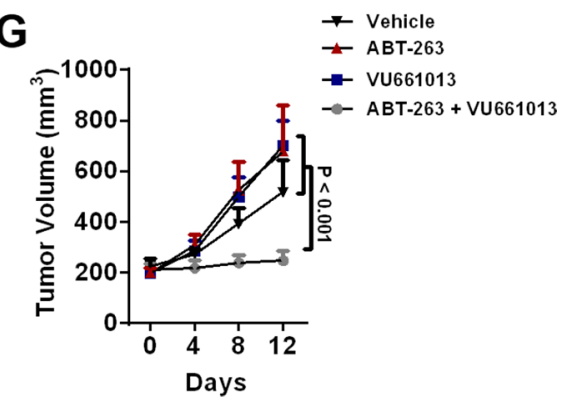

Figure 5: Increased Mcl-1 activity, but not expression, in response to ABT-263 is blocked by the novel Mcl-1 inhibitor VU661013. (A) Western analysis of whole cell lysates harvested from cells treated with $1 \mu \mathrm{M}$ ABT-263 and/or $1 \mu \mathrm{M}$ VU661013 for 16 hrs. Antibodies used for western analysis are shown at left. (B) Caspase 3/7 activity was measured in cells treated with $1 \mu \mathrm{M}$ VU661013 and/or $1 \mu \mathrm{M}$ ABT-263 for $16 \mathrm{hrs}$. Data points are the average RLUs corrected for total protein in three technical replicates, midlines are the average RLUs corrected for total protein of 3-6 biological replicates ( \pm S.E.). The average RLUs in control cells for each cell line was set at a value of 1, Two-way ANOVA. (C) Western analysis of cells expressing shControl or shMcl-1, treated with ABT-263 (1 $\mu$ M) or with DMSO. Antibodies used are shown to left of each panel. Relative Mcl-1 expression was determined using densitometry analysis. (D) Caspase 3/7 activity was measured in cells expressing shControl or shMcl1 shRNA sequences, and treated with $1 \mu$ M ABT-263 for 4 hrs. Data points are the average RLUs corrected for total protein in three technical replicates, midlines are the average RLUs corrected for total protein of 6-9 biological replicates $( \pm$ S.E.). The average RLUs in control cells for each cell line was set at a value of 1, Two-way ANOVA. (E) Cells were grown for 7 days with $1 \mu \mathrm{M}$ VU661013 and/or $1 \mu \mathrm{M}$ ABT-263. Average relative number of cells per well is shown, $\mathrm{N}=6-10$, Two-way ANOVA followed by Tukey's multiple comparison's test. (F-G) MCF7 tumor xenografts in athymic mice were treated with ABT-263 (20 $\mathrm{mg} / \mathrm{kg}$, once daily) and/or VU661013 (25 mg/kg, once weekly) for 12 days. TUNEL analysis was used to detect apoptotic cells in tumors collected on treatment day 12, one hour after final treatment (F). Each data point represents the percentage of TUNEL+ cells in 3 random fields per sample, $\mathrm{N}=6-10$ per group. Tumor volume of MCF7 xenografts were measured once every four days beginning on treatment day $0(\mathrm{G})$. Average tumor volume (S.E.) is shown. $\mathrm{N}=6-10$. 
with Bim in situ in ER+ breast cancer cells using PLA. Interestingly, VU661013-treated ER+ breast cancer cells upregulated Mcl-1 protein levels, as shown by western analysis, although PLA confirmed that Mcl-1 interactions with Bim remained suppressed by VU661013. Mcl-1 upregulation in response to the Mcl-1 inhibitor S68345 has been reported previously in HER2-amplified breast cancers and TNBC $[2,43]$. In contrast to Mcl-1 upregulation upon treatment with VU661013, we did not see upregulation of $\mathrm{Bcl}-2$ or Bcl-xL in ER+ breast cancer cells treated with the Mcl-1 inhibitor. This may suggest that, in ER+ breast cancers, Mcl-1 plays a dominant role among Bcl-2 family members under conditions in which an imbalance of pro- and anti-apoptotic factors threaten cell survival. This hypothesis would require further investigation, but is supported by observations that the MCL1 gene is more frequently amplified and overexpressed in ER+ breast cancers as compared to genes encoding all other Bcl-2 family members combined [11].

In summary, we report here that mTOR-dependent translation of Mcl-1 increases Mcl-1 expression and promotes cell survival in ER+ breast cancer cells. This signaling is elevated in cells treated with the $\mathrm{Bcl}-2 / \mathrm{Bcl}-\mathrm{xL}$ inhibitor ABT-263, but is diminished upon inhibition of mTORC1 using RAD001. Importantly, we have tested the Mcl-1 selective inhibitor VU661013 in ER+ breast cancer cells, finding that Mcl-1 inhibition increases apoptosis and decreases tumor cell death, particularly when used in combination with ABT-263. These studies support further investigation of VU661013 and other emerging Mcl-1 inhibitors in ER+ breast cancers.

\section{MATERIALS AND METHODS}

\section{Cell culture}

All cell lines used in these studies were purchased directly from American Tissue Type Collection (Homo sapiens ATCC CRL 2327; HTB-22; HTB-133), and cultured in growth media [DMEM (Corning Cellgro), 10\% fetal bovine serum (FBS, Life Technologies), 1x antibiotics/anti-mycotics (Life Technologies)]. Mcl-1 expression was stably ablated used lentiviral particles containing two separate shRNA sequences against Mcl-1 (shMCL1), and a scramble control (shControl), according to the manufactures protocol (Santa Cruz Biotechnology, SC-35878-V) and as described previously. Cells were selected with puromycin (Life Technologies). Growth was measured by seeding 2,500 cells in a $35-\mathrm{mm}$ dish, treating with inhibitors $(1.0 \mu \mathrm{M}$ ABT-263, $200 \mathrm{nM}$ RAD001, $1 \mu \mathrm{M}$ VU661013) in growth media after the cells adhered for 16 hr. Caspase-3/7 activity was measured using Caspase-3/7 Glo (Promega). 10,000 cells/well plated in a 96-well dish were treated the following day $\pm 1.0 \mu \mathrm{M}$ ABT-263, 200 nM RAD001, or $1 \mu \mathrm{M}$ VU661013 for $4 \mathrm{hr}$ or $48 \mathrm{hr}$. Mcl-1 protein stability was determined after treatment with 1.0 $\mu \mathrm{M}$ ABT-263 for $16 \mathrm{hr}$ and treatment with CHX $(50 \mu \mathrm{g} /$ $\mathrm{mL}$, Sigma-Aldrich) for the final 0, 15, and $30 \mathrm{~min}$. Whole cell lysates were harvested and analyzed by western analysis according to the above protocol.

\section{RT-qPCR analysis}

RT-qPCR was completed as previously described [44], using human MCL1 primers [Integrated DNA Technologies, Forward (5'-CCTTCCAAGGATGGGTTTGTGGA) and Reverse (5'-TGCCACTTGCTT TTCTGGCT)], Human 36B4 control primers (Integrated DNA Technologies). $\Delta \Delta \mathrm{C}_{\mathrm{t}}$ values were standardized to $36 B 4$ and the average standardized $\Delta \Delta \mathrm{C}_{\mathrm{t}}$ values were presented.

\section{Western analysis and immunoprecipitation}

For western analysis, whole cell lysates were harvested in ice-cold NP-40 lysis buffer (NLB) [50 mM Tris pH 7.4, $100 \mathrm{mM} \mathrm{NaF}, 120 \mathrm{mM} \mathrm{NaCl}, 0.5 \%$ NP-40, $100 \mu \mathrm{M} \mathrm{Na}_{3} \mathrm{VO}_{4}, 1 \mathrm{X}$ protease inhibitor cocktail (Roche), $0.5 \mu \mathrm{M}$ proteasome inhibitor (Santa Cruz Technologies)]. Protein concentration was determined by BCA assay (Pierce) and $20 \mu \mathrm{g}$ protein per sample were resolved on 4-12\% sodium dodecyl sulfate (SDS)-polyacrylamide gel electrophoresis (PAGE) gels (NuPAGE, InVitrogen). For immunoprecipitation, protein $\mathrm{A} / \mathrm{G}$ agarose beads (Santa Cruz Biotechnology) were cross-linked with 10 $\mu \mathrm{g}$ antibody (as indicated) using $5 \mathrm{mM}$ BS3 (SigmaAldrich) at room temperature for $30 \mathrm{~min}$, quenched using $15 \mu \mathrm{L}$ 1.0 M Tris ( $\mathrm{pH}$ 7.4), washed with ice-cold NLB, diluted 1:4 in phosphate buffered saline (PBS, pH 7.4). $10 \mu$ conjugated antibody-beads incubated overnight with $1000 \mu \mathrm{g}$ whole cell lysates collected in NLB. Beads were washed six times with $0.25 \mathrm{X}$ NLB, boiled in $1 \mathrm{x}$ reducing sample buffer (NuPAGE, Invitrogen), and resolved on a $4-12 \%$ SDS-PAGE gel as detailed in [11]. Proteins were transferred to nitrocellulose (iBlot, Invitrogen), blocked in 3\% gelatin (Sigma-Aldrich) in Tris buffered saline (TBS), 0.1\% Tween-20 (Sigma-Aldrich), then probed with primary antibodies [Bim (1:500), Bcl-xL (1:500), and $\beta$-actin $(1: 10,000)$ from Cell Signaling Technology); Mcl-1 (1:500) from Santa Cruz Biotechnology; and Bcl-2 (1:1000) from DAKO], and secondary antibodies [horseradish peroxidase-conjugated donkey anti-rabbit (1:10,000) or donkey anti-mouse (1:5000), Sigma-Aldrich] and developed using enhanced chemi-luminescence (Pierce).

\section{Murine models}

Mice were housed under pathogen-free conditions and all experiments were in accordance with AAALAC guidelines and with Vanderbilt University Institutional Animal Care and Use Committee approval. MCF7 
xenografts were generated as described previously [45]. Tumor volume was measured every other day once tumors became palpable. Treatment of mice began when tumors reached $200 \mathrm{~mm}^{3}$. Mice were treated with once daily with oral RAD001 (2 mg/kg), oral ABT-263 (50 mg/kg), or treated once weekly with VU661013 $(25 \mathrm{mg} / \mathrm{kg})$, by intraperitoneal injection in $50 \mu 1$ vehicle $(2.5 \%$ DMSO, $50 \%$ polyethylene glycol (PEG)-300, $47.5 \%$ sterile saline).

\section{Histological analysis}

All samples were fixed in 10\% formalin, paraffinembedded and $5-\mu \mathrm{m}$ sections were stained with TUNEL using the ApopTag kit (Calbiochem). IHCfor Mcl1, phospho-p70-S6K (Cell Signaling Technologies) and phospho-histone H3 (Santa Cruz Biotechnology) were performed on sections as described [45, 46]. All histological analyses were photographed using Olympus DP2 software (200x).

\section{Proximity ligation assay (PLA)}

Cells cultured in 96-well plates were fixed with methanol and Duolink (Sigma) proximity ligation protocol was used according to manufacturer's directions using Mcl-1 (Santa Cruz Biotechnology, 1:25) and Bim (Santa Cruz Biotechnology, 1:25) antibodies. Cells were counterstained with Hoescht. Plates were scanned by ImageXpress Micro XL Automated Microscope. PLA fluorescent puncta were enumerated using the automated Duolink ImageTool. Puncta per cell values were recorded for $>20$ cells per $400 \mathrm{x}$ field.

\section{Statistical analysis}

Statistical significance $(\mathrm{P}<0.05)$ was determined using Student's unpaired two-tailed $T$-test or ANOVA with Tukey's Multiple Comparisons test, using the Graphpad Prism 6 software. For animal studies significance was determined by area under the curve.

\section{Abbreviations}

ER, estrogen receptor; TNBC, triple negative breast cancer; BH3, Bcl-1 homology-3; Hr, hours; qRTPCR, quantitative real time polymerase chain re action; CHX, cycloheximide; PI3K, phosphatid yl inositol-3 kinase; mTORC1, mTOR Complex 1; 4EBP1, 4-Elongating Initiating Factor Binding Protein-1; PLA, Proximity Ligation Assay; IHC, Imm unohistochemistry; S6K, S6-kinase; TUNEL, Teminal dUTP Nick End Labeling; shRNA, short hairpin RNA; FBS, Fetal Bovine Serum; NLB, Nonident P-40 Lysis Buffer; SDS PAGE, Sodium Dodecyl Sulfate Polyacrylamide Gel Electrophoresis; IP, Immunoprecipitation; PBS, Phosphate Buffered Saline; TBS, Tris buffered Saline.

\section{Author contributions}

Michelle M. Williams designed experiments, performed experiments, interpreted data, generated figures and wrote the manuscript.

David L. Elion performed experiments and aided in discussion.

Donna J. Hicks designed experiments and performed experiments.

Violeta Sanchez performed experiments.

Rebecca S. Cook conceived of project, designed experiments, overviewed data interpretation, edited figure presentation, and wrote manuscript.

\section{ACKNOWLEDGMENTS}

Acknowledgment is owed to Dr. Stephen Fesik who kindly provided VU661013. We extend to additional thanks to those who reviewed this manuscript, including Dr. Stephen Fesik, Dr. Jin Chen, Dr. Thomas Stricker, and Dr. Sandra Zinkel. Additional acknowledgment is owed to the Vanderbilt High Throughput Screening Facility and Joshua Bauer for development of the Proximity Ligation Assay.

\section{CONFLICTS OF INTEREST}

The authors declare no conflicts of interest in the performance, analysis, or presentation of experiments and resulting data herein.

This manuscript and all information herein is not under consideration for publication elsewhere.

\section{FUNDING}

We acknowledge Vanderbilt Shared Resources who contributed to studies reported herein: the VICC Breast SPORE Pathology (Dr. Melinda Sanders), Translational Pathology, Digital Histology, and VANTAGE shared resources. This work was supported by Specialized Program of Research Excellence (SPORE) grant NIH P50 CA098131, Cancer Center Support grant NIH P30 CA68485, CTSA UL1TR000445 from National Center for Advancing Translational Sciences, W81XWH-161-0063 from the Congressionally Directed Medical Research Program and NRSA F31 CA195989-01.

\section{REFERENCES}

1. Williams MM, Cook RS. Bcl-2 family proteins in breast development and cancer: could Mcl-1 targeting overcome therapeutic resistance? Oncotarget. 2015; 6:3519-30. https://doi.org/10.18632/oncotarget.2792. [PubMed]

2. Merino D, Lok SW, Visvader JE, Lindeman GJ. Targeting BCL-2 to enhance vulnerability to therapy in estrogen 
receptor-positive breast cancer. Oncogene. 2016; 35:187787. https://doi.org/10.1038/onc.2015.287. [PubMed]

3. Yip KW, Reed JC. Bcl-2 family proteins and cancer. Oncogene. 2008; 27:6398-406. https://doi.org/10.1038/onc.2008.307. [PubMed]

4. Willis SN, Chen L, Dewson G, Wei A, Naik E, Fletcher JI, et al. Proapoptotic Bak is sequestered by Mcl-1 and Bcl-x(L), but not Bcl-2, until displaced by BH3-only proteins. Genes Dev. 2005; 19:1294-305. https://doi.org/10.1101/gad.1304105. [PubMed]

5. Cheng EH, Wei MC, Weiler S, Flavell RA, Mak TW, Lindsten $\mathrm{T}$, et al. BCL-2, BCL-X(L) sequester BH3 domain-only molecules preventing BAX- and BAKmediated mitochondrial apoptosis. Mol Cell. 2001; 8:70511. https://doi.org/10.1016/S1097-2765(01)00320-3. [PubMed]

6. Dawson SJ, Makretsov N, Blows FM, Driver KE, Provenzano E, Le Quesne J, et al. BCL2 in breast cancer: a favourable prognostic marker across molecular subtypes and independent of adjuvant therapy received. Br J Cancer. 2010; 103:668-75. https://doi.org/10.1038/sj.bjc.6605736. [PubMed]

7. Oakes SR, Vaillant F, Lim E, Lee L, Breslin K, Feleppa $\mathrm{F}$, et al. Sensitization of BCL-2-expressing breast tumors to chemotherapy by the $\mathrm{BH} 3$ mimetic ABT737. Proc Natl Acad Sci U S A. 2012; 109:2766-71. https://doi.org/10.1073/pnas.1104778108. [PubMed]

8. Olopade OI, Adeyanju MO, Safa AR, Hagos F, Mick R, Thompson $\mathrm{CB}$, et al. Overexpression of BCL-x protein in primary breast cancer is associated with high tumor grade and nodal metastases. Cancer J Sci Am. 1997; 3:230-7. [PubMed]

9. Keitel U, Scheel A, Thomale J, Halpape R, Kaulfuss S, Scheel C, et al. Bcl-xL mediates therapeutic resistance of a mesenchymal breast cancer cell subpopulation. Oncotarget. 2014; 5:11778-91. https://doi.org/10.18632/oncotarget.2634. [PubMed]

10. Vaillant F, Merino D, Lee L, Breslin K, Pal B, Ritchie ME, et al. Targeting BCL-2 with the BH3 mimetic ABT-199 in estrogen receptor-positive breast cancer. Cancer Cell. 2013; 24:120-9. https://doi.org/10.1016/j.ccr.2013.06.002. [PubMed]

11. Williams MM, Lee L, Hicks DJ, Joly MM, Elion D, Rahman B, et al. Key survival factor, Mcl1, correlates with sensitivity to combined Bcl-2/ Bcl-xL blockade. Mol Cancer Res. 2017; 15:259-68. https://doi.org/10.1158/1541-7786.MCR-16-0280-T. [PubMed]

12. Ding Q, He X, Xia W, Hsu JM, Chen CT, Li LY, et al. Myeloid cell leukemia-1 inversely correlates with glycogen synthase kinase-3beta activity and associates with poor prognosis in human breast cancer. Cancer Res. 2007; 67:4564-71. https://doi.org/10.1158/0008-5472.CAN-06-1788. [PubMed]
13. Labi V, Grespi F, Baumgartner F, Villunger A. Targeting the Bcl-2-regulated apoptosis pathway by $\mathrm{BH} 3$ mimetics: a breakthrough in anticancer therapy? Cell Death Differ. 2008; 15:977-87. https://doi.org/10.1038/cdd.2008.37. [PubMed]

14. Roberts AW, Seymour JF, Brown JR, Wierda WG, Kipps TJ, Khaw SL, et al. Substantial susceptibility of chronic lymphocytic leukemia to BCL2 inhibition: results of a phase I study of navitoclax in patients with relapsed or refractory disease. J Clin Oncol. 2012; 30:488-96. https://doi.org/10.1200/JCO.2011.34.7898. [PubMed]

15. Wilson WH, O'Connor OA, Czuczman MS, LaCasce AS, Gerecitano JF, Leonard JP, et al. Navitoclax, a targeted high-affinity inhibitor of BCL-2, in lymphoid malignancies: a phase 1 dose-escalation study of safety, pharmacokinetics, pharmacodynamics, and antitumour activity. Lancet Oncol. 2010; 11:1149-59. https://doi.org/10.1016/S1470-2045(10)70261-8. [PubMed]

16. Souers AJ, Leverson JD, Boghaert ER, Ackler SL, Catron ND, Chen J, et al. ABT-199, a potent and selective BCL-2 inhibitor, achieves antitumor activity while sparing platelets. Nat Med. 2013; 19:202-8. https://doi.org/10.1038/nm.3048. [PubMed]

17. Anderson GR, Wardell SE, Cakir M, Crawford L, Leeds JC, Nussbaum DP, et al. PIK3CA mutations enable targeting of a breast tumor dependency through mTOR-mediated MCL-1 translation. Sci Transl Med. 2016; 8:369ra175. https://doi.org/10.1126/scitranslmed.aae0348. [PubMed]

18. Mills JR, Hippo Y, Robert F, Chen SM, Malina A, Lin CJ, et al. mTORC1 promotes survival through translational control of Mcl-1. Proc Natl Acad Sci U S A. 2008; 105:10853-8. https://doi.org/10.1073/pnas.0804821105. [PubMed]

19. Willimott S, Beck D, Ahearne MJ, Adams VC, Wagner SD. Cap-translation inhibitor, 4EGI-1, restores sensitivity to ABT-737 apoptosis through cap-dependent and -independent mechanisms in chronic lymphocytic leukemia. Clin Cancer Res. 2013; 19:3212-23. https://doi.org/10.1158/1078-0432.CCR-12-2185. [PubMed]

20. Cencic R, Hall DR, Robert F, Du Y, Min J, Li L, et al. Reversing chemoresistance by small molecule inhibition of the translation initiation complex eIF4F. Proc Natl Acad Sci U S A. 2011; 108:1046-51. https://doi.org/10.1073/pnas.1011477108. [PubMed]

21. Tao ZF, Hasvold L, Wang L, Wang X, Petros AM, Park $\mathrm{CH}$, et al. Discovery of a potent and selective BCL-XL inhibitor with in vivo activity. ACS Med Chem Lett. 2014; 5:1088-93. https://doi.org/10.1021/ml5001867. [PubMed]

22. Silvera D, Formenti SC, Schneider RJ. Translational control in cancer. Nat Rev Cancer. 2010; 10:254-66. https://doi.org/10.1038/nrc2824. [PubMed]

23. Moschetta M, Reale A, Marasco C, Vacca A, Carratu MR. Therapeutic targeting of the mTOR-signalling pathway in cancer: benefits and limitations. Br J Pharmacol. 2014; 171:3801-13. https://doi.org/10.1111/bph.12749. [PubMed] 
24. Schuurman HJ, Cottens S, Fuchs S, Joergensen J, Meerloo T, Sedrani R, et al. SDZ RAD, a new rapamycin derivative: synergism with cyclosporine. Transplantation. 1997; 64:325. https://doi.org/10.1097/00007890-199707150-00007. [PubMed]

25. Williams MM, Lee L, Werfel T, Joly MMM, Hicks DJ, Rahman B, et al. Intrinsic apoptotic pathway activation increases response to anti-estrogens in luminal breast cancers. Cell Death Dis. 2018; 9:21. https://doi.org/10.1038/s41419-017-0072-x. [PubMed]

26. Ramsey HE, Fischer MA, Lee T, Gorska AE, Arrate MP, Fuller L, et al. A novel MCL1 inhibitor combined with venetoclax rescues venetoclax-resistant acute myelogenous leukemia. Cancer Discov. 2018; 8:1566-81. https://doi.org/10.1158/2159-8290.CD-18-0140. [PubMed]

27. Lee T, Christov PP, Shaw S, Tarr JC, Zhao B, Veerasamy N, et al. Discovery of potent myeloid cell leukemia-1 (Mcl-1) inhibitors that demonstrate in vivo activity in mouse xenograft models of human cancer. J Med Chem. 2019; 62:3971-3988. https://doi.org/10.1021/acs.jmedchem.8b01991. [PubMed]

28. Kotschy A, Szlavik Z, Murray J, Davidson J, Maragno AL, Le Toumelin-Braizat G, et al. The MCL1 inhibitor S63845 is tolerable and effective in diverse cancer models. Nature. 2016; 538:477-82. https://doi.org/10.1038/nature19830. [PubMed]

29. Lee T, Bian Z, Zhao B, Hogdal LJ, Sensintaffar JL, Goodwin $\mathrm{CM}$, et al. Discovery and biological characterization of potent myeloid cell leukemia-1 inhibitors. FEBS Lett. 2017; 591:240-51. https://doi.org/10.1002/1873-3468.12497. [PubMed]

30. Xiao Y, Nimmer P, Sheppard GS, Bruncko M, Hessler P, Lu $\mathrm{X}$, et al. MCL-1 is a key determinant of breast cancer cell survival: validation of MCL-1 dependency utilizing a highly selective small molecule inhibitor. Mol Cancer Ther. 2015; 14:1837-47. https://doi.org/10.1158/1535-7163.MCT-14-0928. [PubMed]

31. Hynes NE, Boulay A. The mTOR pathway in breast cancer. J Mammary Gland Biol Neoplasia. 2006; 11:5361. https://doi.org/10.1007/s10911-006-9012-6. [PubMed]

32. Ballinger TJ, Meier JB, Jansen VM. Current landscape of targeted therapies for hormone-receptor positive, HER2 negative metastatic breast cancer. Front Oncol. 2018; 8:308. https://doi.org/10.3389/fonc.2018.00308. [PubMed]

33. Showkat M, Beigh MA, Andrabi KI. mTOR signaling in protein translation regulation: implications in cancer genesis and therapeutic interventions. Mol Biol Int. 2014; 2014:686984. https://doi.org/10.1155/2014/686984. [PubMed]

34. Schatz JH, Oricchio E, Wolfe AL, Jiang M, Linkov I, Maragulia J, et al. Targeting cap-dependent translation blocks converging survival signals by AKT and PIM kinases in lymphoma. J Exp Med. 2011; 208:1799-807. https://doi.org/10.1084/jem.20110846. [PubMed]
35. Cope CL, Gilley R, Balmanno K, Sale MJ, Howarth $\mathrm{KD}$, Hampson $\mathrm{M}$, et al. Adaptation to mTOR kinase inhibitors by amplification of eIF4E to maintain capdependent translation. J Cell Sci. 2014; 127:788-800. https://doi.org/10.1242/jcs.137588. [PubMed]

36. Faber AC, Coffee EM, Costa C, Dastur A, Ebi H, Hata AN, et al. mTOR inhibition specifically sensitizes colorectal cancers with KRAS or BRAF mutations to BCL-2/BCL-XL inhibition by suppressing MCL-1. Cancer Discov. 2014; 4:42-52. https://doi.org/10.1158/2159-8290.CD-13-0315. [PubMed]

37. Preuss E, Hugle M, Reimann R, Schlecht M, Fulda S. Pan-mammalian target of rapamycin (mTOR) inhibitor AZD8055 primes rhabdomyosarcoma cells for ABT-737-induced apoptosis by down-regulating Mcl-1 protein. J Biol Chem. 2013; 288:35287-96. https://doi.org/10.1074/jbc.M113.495986. [PubMed]

38. Gardner EE, Connis N, Poirier JT, Cope L, Dobromilskaya I, Gallia GL, et al. Rapamycin rescues ABT-737 efficacy in small cell lung cancer. Cancer Research. 2014; 74:284656. https://doi.org/10.1158/0008-5472.CAN-13-3460. [PubMed]

39. Faber AC, Farago AF, Costa C, Dastur A, GomezCaraballo M, Robbins R, et al. Assessment of ABT263 activity across a cancer cell line collection leads to a potent combination therapy for small-cell lung cancer. Proc Natl Acad Sci U S A. 2015; 112:E1288-96. https://doi.org/10.1158/1538-7445.AM2014-2933. [PubMed]

40. Quartararo CE, Reznik E, deCarvalho AC, Mikkelsen T, Stockwell BR. High-throughput screening of patientderived cultures reveals potential for precision medicine in glioblastoma. ACS Med Chem Lett. 2015; 6:948-52. https://doi.org/10.1021/acsmedchemlett.5b00128. [PubMed]

41. Jebahi A, Villedieu M, Petigny-Lechartier C, Brotin E, Louis MH, Abeilard E, et al. PI3K/mTOR dual inhibitor NVP-BEZ235 decreases Mcl-1 expression and sensitizes ovarian carcinoma cells to Bcl-xL-targeting strategies, provided that Bim expression is induced. Cancer Lett. 2014; 348:38-49. https://doi.org/10.1016/j.canlet.2014.03.001. [PubMed]

42. Wheler JJ, Atkins JT, Janku F, Moulder SL, Yelensky R, Stephens PJ, et al. Multiple gene aberrations and breast cancer: lessons from super-responders. BMC Cancer. 2015; 15:442. https://doi.org/10.1186/s12885-015-1439-y. [PubMed]

43. Vallet S, Fan F, Malvestiti S, Pecherstorfer M, Sattler M, Schneeweiss A, et al. Rationally derived drug combinations with the novel Mcl-1 inhibitor EU-5346 in breast cancer. Breast Cancer Res Treat. 2019; 173:585-96. https://doi.org/10.1007/s10549-018-5022-5. [PubMed]

44. Stanford JC, Young C, Hicks D, Owens P, Williams A, Vaught DB, et al. Efferocytosis produces a prometastatic landscape during postpartum mammary gland involution. J Clin Invest. 2014; 124:0-. https://doi.org/10.1172/JCI76375. [PubMed] 
45. Morrison MM, Hutchinson $\mathrm{K}$, Williams MM, Stanford JC, Balko JM, Young C, et al. ErbB3 downregulation enhances luminal breast tumor response to antiestrogens. J Clin Invest. 2013; 123:4329-43. https://doi.org/10.1172/JCI66764. [PubMed]
46. Qu S, Rinehart $\mathrm{C}, \mathrm{Wu} \mathrm{HH}$, Wang SE, Carter B, Xin H, et al. Gene targeting of ErbB3 using a Cre-mediated unidirectional DNA inversion strategy. Genesis. 2006; 44:477-86. https://doi.org/10.1002/dvg.20243. [PubMed] 